\title{
Reid's Critique of Leibniz Notion of Free Agency
}

\author{
L. Holland \\ King's College London 1
}

\begin{abstract}
Dissatisfied with Bayle's statement, but noting what he believed to be mistakes made by scholasticism, Leibniz sought to figure out an answer to Bayle's problems trying to avoid repeating those scholastic mistakes. According to Leibniz, the reason of such inaccuracies is that Scholastic philosophy "in addition to its own faults, which were very great, found itself burdened with those of theology" (Theodicy, §6). Leibniz proposed then to develop the Theodicy. Nevertheless, what is a theodicy about? From Leibniz's Theodicy, it is all about defending that reason would have enough strength to wrestle with scepticism and, therefore, demonstrating reason could dissolve, indeed, some issues faced by Christian dogmas. These issues are majorly three, and they name the subtitle of Leibniz's Theodicy: Essays on the Goodness of God, the Freedom of Man and the Origin of Evil. These three points, individually, do not constitute as much trouble as when it is tried to conciliate all of them together, at this point the most of serious issues come about. Thereby, by focusing on the problem of free will, this work aims at explaining Reid's critique of Leibniz's notion of free agency considering that, for the German philosopher, everything in our world is completely predetermined, but humans are free. Besides, it is argued that Reid's critique of Leibniz's approach to the notion of free action can fill up some possible gaps left by the latter and clarify some tricky issues related to free agency.
\end{abstract}

Keywords: action, change, free agency, freedom, philosophy of action. 